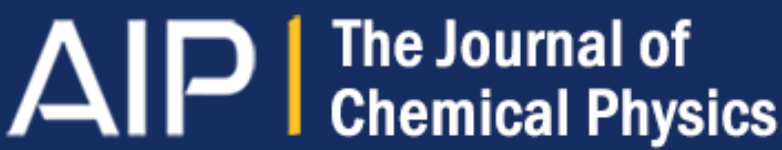

\section{Hydrated hydride anion clusters}

Han Myoung Lee, Dongwook Kim, N. Jiten Singh, Maciej Kołaski, and Kwang S. Kim

Citation: The Journal of Chemical Physics 127, 164311 (2007); doi: 10.1063/1.2778423

View online: http://dx.doi.org/10.1063/1.2778423

View Table of Contents: http://scitation.aip.org/content/aip/journal/jcp/127/16?ver=pdfcov

Published by the AIP Publishing

Articles you may be interested in

Infrared spectroscopy of hydrated naphthalene cluster anions

J. Chem. Phys. 137, 104303 (2012); 10.1063/1.4750371

Hydration of $\mathrm{Li}+$-ion in atom-bond electronegativity equalization method-7P water: A molecular dynamics simulation study

J. Chem. Phys. 122, 084514 (2005); 10.1063/1.1853372

Dissolution of a base $(\mathrm{RbOH})$ by water clusters

J. Chem. Phys. 121, 4665 (2004); 10.1063/1.1779573

Structures, energetics, and spectra of hydrated hydroxide anion clusters

J. Chem. Phys. 121, 4657 (2004); 10.1063/1.1779566

Dissociation chemistry of hydrogen halides in water

J. Chem. Phys. 120, 9524 (2004); 10.1063/1.1711596

How can you REACH $100 \%$

of researchers at the Top 100

Physical Sciences Universities?

With The Journal of Chemical Physics.

AIP $\left.\right|_{\text {Chemical Physics }} ^{\text {The Journal of }}$

THERE'S POWER IN NUMBERS. Reach the world with AIP Publishing.

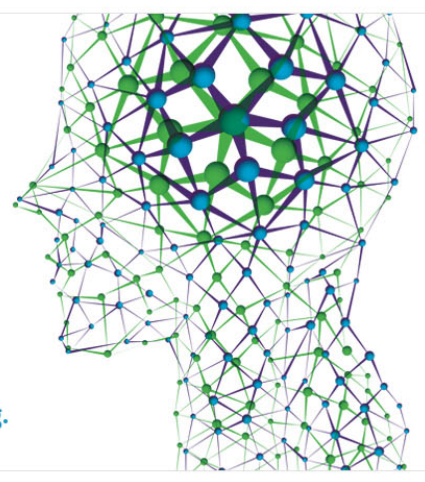




\title{
Hydrated hydride anion clusters
}

\author{
Han Myoung Lee ${ }^{\mathrm{a})}$ \\ Department of Chemistry, Pohang University of Science and Technology, Pohang 790-784, Korea and \\ Center for Basic Sciences, Pohang University of Science and Technology, Pohang 790-784, Korea
}

\author{
Dongwook Kim, N. Jiten Singh, Maciej Kołaski, ${ }^{\text {b) }}$ and Kwang S. Kim ${ }^{\mathrm{c})}$ \\ Center for Superfunctional Materials, Department of Chemistry, Pohang University of Science and \\ Technology, San 31, Hyojadong, Namgu, Pohang 790-784, Korea
}

(Received 11 June 2007; accepted 7 August 2007; published online 25 October 2007)

\begin{abstract}
On the basis of density functional theory (DFT) and high level ab initio theory, we report the structures, binding energies, thermodynamic quantities, IR spectra, and electronic properties of the hydride anion hydrated by up to six water molecules. Ground state DFT molecular dynamics simulations (based on the Born-Oppenheimer potential surface) show that as the temperature increases, the surface-bound hydride anion changes to the internally bound structure. Car-Parrinello molecular dynamics simulations are also carried out for the spectral analysis of the monohydrated hydride. Excited-state $a b$ initio molecular dynamics simulations show that the photoinduced charge-transfer-to-solvent phenomena are accompanied by the formation of the excess electron-water clusters and the detachment of the $\mathrm{H}$ radical from the clusters. The dynamics of the detachment process of a hydrogen radical upon the excitation is discussed. (C) 2007 American Institute of Physics. [DOI: 10.1063/1.2778423]
\end{abstract}

\section{INTRODUCTION}

The hydride ion, which is the smallest anion and a strong reducing agent as one of the strongest bases known, shows intriguing features in chemically and biologically important reduction-oxidation reactions. ${ }^{1}$ Only the alkali and alkali earth metals can reduce the molecular hydrogen to the hydride anion. The electron-attachment processes to form the hydride ion or hydrated hydride ion can be described as follows: $\quad \mathrm{H}^{+}+e^{-} \rightarrow \mathrm{H} \cdot ; \quad \mathrm{H} \cdot+e^{-} \rightarrow \mathrm{H}^{-} \quad$ and $\quad \mathrm{H}^{+}\left(\mathrm{H}_{2} \mathrm{O}\right)_{n}+e^{-}$ $\rightarrow \mathrm{H} \cdot\left(\mathrm{H}_{2} \mathrm{O}\right)_{n} ; \mathrm{H} \cdot\left(\mathrm{H}_{2} \mathrm{O}\right)_{n}+e^{-} \rightarrow \mathrm{H}^{-}\left(\mathrm{H}_{2} \mathrm{O}\right)_{n}$. However, the hydride ion is hardly present in solutions, as it reacts with most solvents except alkanes. The hydride ion formed as an intermediate is involved in biologically important reduction processes of nicotinamide adenine dinucleotide $\left(\mathrm{NAD}^{+}\right)$, nicotinamide adenine dinucleotide phosphate $\left(\mathrm{NADP}^{+}\right)$, flavin mononucleotide $(\mathrm{FMN})$, and flavin adenine dinucleotide (FAD) (e.g., $\mathrm{NAD}^{+}+\mathrm{H}^{+}+2 e-=\mathrm{NADH} ; \mathrm{FMN}+2 \mathrm{H}^{+}+2 e-$ $\left.=\mathrm{FMNH}_{2}\right)^{2}$

Another interesting point about the hydride ion is found from alkali metal hydrides which are very reactive. ${ }^{3}$ Though this study is difficult in cluster scale, its coordination chemistry involved with solvation is important. Hydration or photoexcitation of alkali metal hydrides provides hydride anions which are easily hydrated like halide anions. The alkali metal hydrides $\left(\mathrm{NaBH}_{4}, \mathrm{LiAlH}_{4}\right)$ react with water molecules and produce the hydroxide anion through the proton transfer process. Boron-hydride $\left(\mathrm{BH}_{3}\right)$ and aluminum-hydride $\left(\mathrm{AlH}_{3}\right)$ show coordination bonding with water molecules. Gold hy-

\footnotetext{
${ }^{a)}$ Electronic mail: abcd0lhm @ postech.ac.kr

${ }^{b)}$ Permanent address: Department of Theoretical Chemistry, Institute of Chemistry, University of Silesia, Szkolna 9, 40-006 Katowice, Poland.

${ }^{c)}$ Electronic mail: kim@postech.ac.kr
}

dride $\left(\mathrm{AuH}_{1-3}\right)$ (Ref. 4) and gold hydride anions $\left(\mathrm{Au}_{n} \mathrm{H}^{-}\right)$ (Ref. 5) were experimentally observed and discussed for their binding energies with an excess electron.

The hydration chemistry of the hydride ion is thus an important subject. There has been a report on the dissociation of water by hydride $\left(\mathrm{H}^{-}+\mathrm{H}_{2} \mathrm{O} \rightarrow \mathrm{OH}^{-}+\mathrm{H}_{2}\right){ }^{6}$ Several solvation studies of the hydride ion by water ${ }^{7}$ and ammonia ${ }^{8}$ were carried out experimentally. The role of the hydride ion in the proton transfer in solvents was discussed, ${ }^{9}$ and $a b$ initio studies of the structures of mono- to trihydrated hydride ions were reported. ${ }^{10}$ Here, we investigate the solvation and coordination chemistry of the hydride ion hydrated by up to six water molecules using high level ab initio calculations. Their hydration structures, energetics, electronic properties, spectra, dynamics, and their ground state density functional theory (DFT) and excited-state ab initio molecular dynamics (ES-AIMD) simulation results will be discussed.

\section{CALCULATION METHODS}

The structures of hydrated hydride ions were investigated using the DFT of Becke's three parameters for exchange and Lee-Yang-Parr correlation functionals (B3LYP) with $6-311++\mathrm{G}^{* * *}$ basis set: [B3LYP/6-311++ $\mathrm{G}^{* *}$ ] and the Möller-Plesset second-order perturbation (MP2) method with the aug-cc-pVDZ basis set containing the $(2 s 2 p / 2 s)$ diffuse functions ${ }^{11}$ (abbreviated as aVDZ+). In order to obtain more accurate interaction energies, coupled cluster theory with singles, doubles, and perturbative triples excitation $[\mathrm{CCSD}(\mathrm{T})]$ calculations using aVDZ+ and aVTZ+ [the augcc-pVTZ basis set with the $(2 s 2 p / 2 s)$ diffuse functions] basis sets were performed at the MP2/aVDZ+ geometries. The electron affinities (EAs) of the hydrogen atom are calculated to be $0.87 \mathrm{eV}$ at B3LYP, $0.35 \mathrm{eV}$ at MP2, and $0.69 \mathrm{eV}$ at the 
$\operatorname{CCSD}(\mathrm{T})$ level of theory (experimental EA: ${ }^{12} 0.75 \mathrm{eV}$ ). The interaction energies $(\Delta E)$ were evaluated with $50 \%$ basis set superposition error (BSSE), to denote the BSSE-corrected and uncorrected values as the lower and upper limits, since the energies with and without BSSE tend to be underestimated and overestimated, respectively. ${ }^{13}$ In this regard, the complete basis set $(\mathrm{CBS})$ limit binding energies $\left(E_{\mathrm{CBS}}\right)$ based on the extrapolation scheme which utilizes $\left(E_{\mathrm{CBS}}\right)=\left[E_{N} N^{3}\right.$ $\left.-E_{N-1}(N-1)^{3}\right] /\left[N^{3}-(N-1)^{3}\right]$, in consideration that the electron correlation approximately increases with $N^{-3}$ for a series of aVNZ basis sets, ${ }^{14}$ are also reported up to the trihydrated hydride anion clusters at the $\operatorname{CCSD}(\mathrm{T})$ level. Vibrational frequency calculations were carried out at the B3LYP/6-311 $++\mathrm{G}^{* *}$ level. The zero point energies (ZPEs) and the resulting enthalpy changes $\left(\Delta H_{r}\right)$ and free energy changes $\left(\Delta G_{r}\right)$ at room temperature and $1 \mathrm{~atm}$ were obtained by using the B3LYP/6-311 $+\mathrm{G}^{* *}$ thermal energies. The configuration interaction with single excitation (CIS) and the random phase approximation $^{15}$ (RPA) at the B3LYP/6-311++ $\mathrm{G}^{* *}$ level were used for the excited-state calculation. These calculations were carried out by using a GAUSSIAN03 suite of programs. ${ }^{16}$ For the analysis of interaction energy components, symmetry-adapted perturbation theory (SAPT) was used. $^{17}$ The ground state DFT molecular dynamics (DFTMD) simulations based on the Born-Oppenheimer potential surface (BOMD) were carried out for the study of temperature effect on the ground state. For the study of the photoexcited-state dynamics, the excited-state $a b$ initio MD (ES-AIMD) simulations were performed by using the HONDO suite of programs. ${ }^{18}$ Here, the B3LYP/6-311++ $\mathrm{G}^{* *}$ method and the complete active space self-consistent field (CASSCF) method with the active space of six electrons and six orbitals $(6,6)$ using the aVDZ+ basis set were used for the photodynamics of the hydrated hydride clusters. For the spectral analysis of the monohydrated hydride, CarParrinello molecular dynamics (CPMD) simulations ${ }^{19}$ were performed at $100 \mathrm{~K}$. Here, the BLYP pseudopotentials were used. A fictitious electron mass of 600 a.u. and an integration step of $\Delta t=0.1$ fs were used. The power spectrum was obtained from the Fourier transform of the velocity autocorrelation function. Most figures were drawn using the Postech Molecular Modeling package. ${ }^{20}$

\section{RESULTS AND DISCUSSION}

\section{A. Structures and interaction energies}

The low-lying energy conformers for mono- to hexahydrated hydride ions are shown in Fig. 1. To obtain the lowest energy conformers, we have investigated many possible structures of various topologies along with diverse hydration structures of anion-water clusters ${ }^{21-23}$ and electron-water clusters. ${ }^{24}$ The ZPE uncorrected $\left(\Delta E_{e}\right)$ and corrected $\left(\Delta E_{0}\right)$ interaction energies for various structures of hydrated hydride anions are listed in Table I. Among these structures, the lowest energy conformers of mono- to hexahydrated hydride anions $(n=1-6)$ in $\Delta E_{0}$ are $1 \mathrm{Cs}, 2 \mathrm{C} 1,3 \mathrm{C} 3,4 \mathrm{Y} 31,5 \mathrm{Y} 32$, and 6 Y42 (Fig. 2). These structures are found to have mono- to tetracoordination. As the temperature increases from 0 to $298 \mathrm{~K}$, the lowest energy structures in $\Delta G_{r}$ for $n$

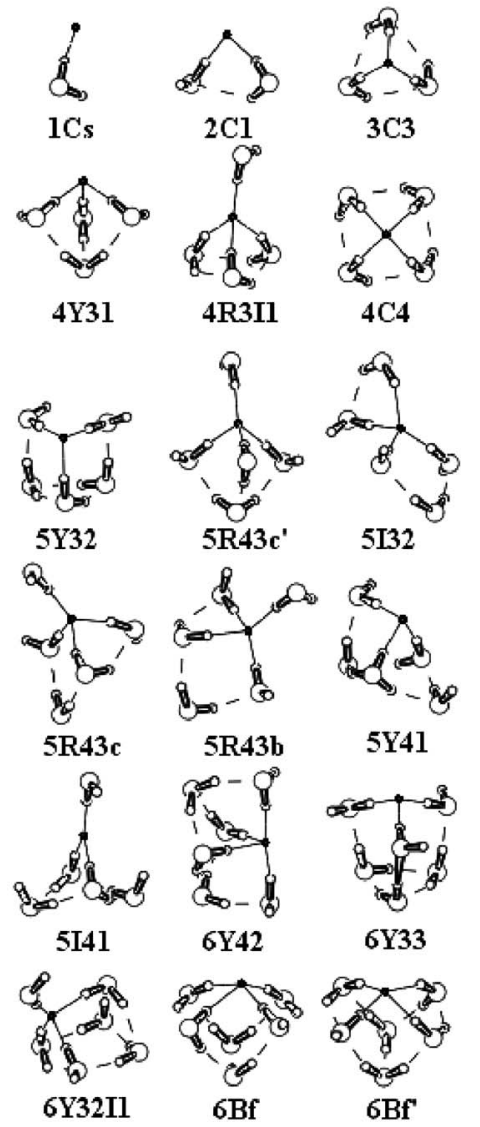

FIG. 1. Low-energy structures of hydrated hydride ions $\left[\mathrm{H}^{-}\left(\mathrm{H}_{2} \mathrm{O}\right)_{1-6}\right]$.

$=4 / 5 / 6$ changes the conformation from $4 \mathrm{Y} 31 / 5 \mathrm{Y} 32 / 6 \mathrm{Y} 42$ to 4R3I1/5I32/6Y32I1 due to the entropy effect (Fig. 2). The hydration energies (in $\Delta E_{0}$ ) of the mono- to hexahydrated hydride anions are $-18.4(-16.4), \quad-33.2(-30.7)$, $-45.5(-43.7), \quad-57.7(-55.8), \quad-68.8(-66.8), \quad$ and $-78.9(-77.5) \mathrm{kcal} / \mathrm{mol}$ at the B3LYP $/ 6-311++\mathrm{G}^{* *}$ (MP2/aVDZ+) level. The CCSD(T) hydration energies $\left(\Delta E_{0}\right)$ for $n=1-3$ at the complete basis set (CBS) limit based on the extrapolation scheme $^{14}$ are $-15.2,-29.6$, and $-43.2 \mathrm{kcal} / \mathrm{mol}$, which are similar to the $50 \%$ BSSEcorrected MP2/aVDZ+ energies. The successive hydration energies $\left(\Delta \Delta E_{0}\right)$ from mono- to hexahydrated hydride anions are $-16.4,-14.3,-13.0,-12.1,-11.0$, and $-10.7 \mathrm{kcal} / \mathrm{mol}$, respectively, at the MP2/aVDZ+ level.

Although a fluoride ion and a superoxide radical ion upon the hydration are internally bound structures, ${ }^{22}$ a hydride ion upon the hydration by a few water molecules has a surface-bound structure such as $\mathrm{OH}^{-}, \mathrm{Cl}^{-}, \mathrm{Br}^{-}$, and $\mathrm{I}^{-} .{ }^{23}$ However, since the ion size of hydride is small, the conformations of penta- and hexahydrated hydride clusters at $0 \mathrm{~K}$ are $5 \mathrm{Y} 32$ and $6 \mathrm{Y} 42$, similar to the conformations of $\mathrm{F}^{-}\left(\mathrm{H}_{2} \mathrm{O}\right)_{5,6}{ }^{22}$

\section{B. Energy decomposition}

The hydration energy (i.e., interaction energy: $\Delta E_{\text {int }}$ ) of the monohydrated hydride anion was analyzed in terms of electrostatic $\left(\Delta E_{\mathrm{es}}\right)$, induction $\left(\Delta E_{\text {ind }}\right)$, dispersion $\left(\Delta E_{\text {disp }}\right)$, and exchange $\left(\Delta E_{\text {ex }}\right)$ energies at the SAPT:MP2/aVDZ+ 
TABLE I. Hydration energies of hydrated hydride anions. (Interaction energies were corrected by 50\% BSSEs by which the lower and upper limit is the BSSE corrected and uncorrected values, respectively. The B3LYP thermal energies were used in all results.)

\begin{tabular}{|c|c|c|c|c|c|c|c|c|c|}
\hline \multirow[b]{2}{*}{$n$} & \multirow[b]{2}{*}{ Conf. } & \multicolumn{4}{|c|}{ B3LYP/6-311++ } & \multicolumn{4}{|c|}{ MP2/aVDZ+ } \\
\hline & & $-\Delta E_{e}$ & $-\Delta E_{0}$ & $-\Delta H_{r}$ & $-\Delta G_{r}$ & $-\Delta E_{e}$ & $-\Delta E_{0}$ & $-\Delta H_{r}$ & $-\Delta G_{r}$ \\
\hline 1 & $1 \mathrm{Cs}$ & $19.7 \pm 0.1$ & 18.4 & 19.7 & 13.7 & $17.7 \pm 0.4$ & 16.4 & 17.6 & 11.7 \\
\hline 2 & $2 \mathrm{C} 1$ & $37.1 \pm 0.4$ & 33.2 & 35.3 & 21.8 & $34.6 \pm 0.9$ & 30.7 & 32.8 & 19.3 \\
\hline 3 & $3 \mathrm{C} 3$ & $52.6 \pm 0.9$ & 45.5 & 48.6 & 25.3 & $50.8 \pm 1.8$ & 43.7 & 46.8 & 23.5 \\
\hline \multirow[t]{3}{*}{4} & $4 Y 31$ & $68.0 \pm 1.5$ & 57.7 & 61.9 & 28.8 & $66.1 \pm 2.6$ & 55.8 & 60.0 & 26.9 \\
\hline & $4 \mathrm{R} 3 \mathrm{I} 1$ & $65.9 \pm 1.3$ & 56.7 & 60.0 & 30.1 & $64.1 \pm 2.2$ & 54.9 & 58.2 & 28.3 \\
\hline & $4 \mathrm{C} 4$ & $65.5 \pm 1.3$ & 55.4 & 59.2 & 26.5 & $64.1 \pm 2.4$ & 54.0 & 57.8 & 25.0 \\
\hline \multirow[t]{7}{*}{5} & $5 Y 32$ & $82.1 \pm 2.2$ & 68.8 & 74.0 & 30.8 & $80.1 \pm 3.6$ & 66.8 & 71.9 & 28.7 \\
\hline & $5 \mathrm{R} 43 \mathrm{c}^{\prime}$ & $80.1 \pm 1.8$ & 68.0 & 72.2 & 33.0 & $78.4 \pm 3.2$ & 66.3 & 70.5 & 31.3 \\
\hline & $5 \mathrm{I} 32$ & $79.8 \pm 1.8$ & 68.2 & 72.2 & 33.6 & $77.8 \pm 3.0$ & 66.2 & 70.1 & 31.6 \\
\hline & $5 \mathrm{R} 43 \mathrm{c}$ & $80.0 \pm 1.8$ & 67.2 & 71.9 & 29.9 & $78.6 \pm 3.4$ & 65.8 & 70.5 & 28.5 \\
\hline & $5 \mathrm{R} 43 \mathrm{~b}$ & $79.2 \pm 1.7$ & 67.7 & 71.6 & 33.3 & & & & \\
\hline & $5 Y 41$ & $80.7 \pm 2.1$ & 67.3 & 72.4 & 29.0 & & & & \\
\hline & $5 \mathrm{I} 41$ & $78.1 \pm 1.9$ & 66.2 & 70.8 & 30.9 & & & & \\
\hline \multirow[t]{5}{*}{6} & $6 Y 42$ & $95.4 \pm 2.7$ & 78.9 & 84.8 & 31.6 & $94.0 \pm 4.4$ & 77.5 & 83.4 & 30.2 \\
\hline & $6 Y 33$ & $94.9 \pm 2.7$ & 79.2 & 84.9 & 32.9 & $91.8 \pm 4.2$ & 76.0 & 81.7 & 29.7 \\
\hline & $6 Y 32 \mathrm{I} 1$ & $93.9 \pm 2.5$ & 78.4 & 83.8 & 33.3 & & & & \\
\hline & $6 \mathrm{Bf}$ & $94.3 \pm 2.8$ & 77.9 & 83.9 & 30.4 & & & & \\
\hline & $6 \mathrm{Bf}^{\prime}$ & $94.2 \pm 2.8$ & 77.7 & 83.8 & 30.2 & & & & \\
\hline \multirow[t]{2}{*}{$n$} & Conf. & \multicolumn{4}{|c|}{$\mathrm{CCSD}(\mathrm{T}) / \mathrm{aVDZ}+$} & \multicolumn{4}{|c|}{$\mathrm{CCSD}(\mathrm{T}) / \mathrm{aVTZ}+$} \\
\hline & & $-\Delta E_{e}$ & $-\Delta E_{0}$ & $-\Delta H_{r}$ & $-\Delta G_{r}$ & $-\Delta E_{e}$ & $-\Delta E_{0}$ & $-\Delta H_{r}$ & $-\Delta G_{r}$ \\
\hline 1 & $1 \mathrm{Cs}$ & $15.5 \pm 0.3$ & 14.1 & 15.4 & 9.4 & $16.2 \pm 0.1$ & 14.9 & 16.2 & 10.2 \\
\hline 2 & $2 \mathrm{C} 1$ & $31.8 \pm 0.8$ & 27.8 & 29.9 & 16.4 & $33.2 \pm 0.4$ & 29.2 & 31.3 & 17.8 \\
\hline 3 & $3 \mathrm{C} 3$ & $48.1 \pm 1.5$ & 40.9 & 44.0 & 20.8 & $49.9 \pm 0.7$ & 42.8 & 45.9 & 22.6 \\
\hline \multirow[t]{2}{*}{$n$} & Conf. & \multicolumn{8}{|c|}{$\operatorname{CCSD}(\mathrm{T}) / \mathrm{CBS}$} \\
\hline & & \multicolumn{2}{|c|}{$-\Delta E_{e}$} & \multicolumn{2}{|c|}{$-\Delta E_{0}$} & \multicolumn{2}{|c|}{$-\Delta H_{r}$} & \multicolumn{2}{|c|}{$-\Delta G_{r}$} \\
\hline 1 & $1 \mathrm{Cs}$ & \multicolumn{2}{|c|}{16.5} & \multicolumn{2}{|c|}{15.2} & \multicolumn{2}{|c|}{16.5} & \multicolumn{2}{|c|}{10.5} \\
\hline 2 & $2 \mathrm{C} 1$ & \multicolumn{2}{|c|}{33.6} & \multicolumn{2}{|c|}{29.6} & \multicolumn{2}{|c|}{31.7} & \multicolumn{2}{|c|}{18.2} \\
\hline 3 & $3 \mathrm{C} 3$ & \multicolumn{2}{|c|}{50.3} & \multicolumn{2}{|c|}{43.2} & \multicolumn{2}{|c|}{46.3} & \multicolumn{2}{|c|}{23.0} \\
\hline
\end{tabular}

level. The induction energy $(34.9 \mathrm{kcal} / \mathrm{mol})$ which is larger than the electrostatic energy, is considerably large, as compared with other mono-hydrated anions, as shown in Fig. 3. The dispersion energy due to the increased polarization is large, and so is the exchange repulsion.

\section{Proton transfer from the water to the hydride anion in the monohydrated hydride}

The proton transfer process from the water molecule to the hydride ion is possible because of the low-energy transition barrier. The potential energy barrier from the monohydrated hydride to the dissociated $\mathrm{OH}^{-}$and detached $\mathrm{H}_{2}$ is estimated to be low $[3.40,1.79$, and $4.68 \mathrm{kcal} / \mathrm{mol}$ at the B3LYP/6-311++ ${ }^{* *}, \mathrm{MP} 2 / \mathrm{aVDZ}+$, and $\operatorname{CCSD}(\mathrm{T}) / \mathrm{aVTZ}$ $+/ / \operatorname{CCSD}(\mathrm{T}) / \mathrm{aVDZ}+$ levels of theory, respectively], while the monohydrated hydride anion is more stable than the system comprised of the detached hydrogen-molecule and the hydroxide anion by about 3.2 and $2.8 \mathrm{kcal} / \mathrm{mol}$ at the B3LYP/6-311++ ${ }^{* *}$ and $\operatorname{CCSD}(\mathrm{T}) / \mathrm{aVTZ}+/ / \operatorname{CCSD}(\mathrm{T}) /$ aVDZ+ levels, respectively (Fig. 4).

\section{Geometric parameters and electronic properties of hydrated hydrides}

It is interesting to note that the hydride ion forms the dihydrogen bond ${ }^{25}$ with the positively charged $\mathrm{H}$ atom in a water molecule. The geometric parameters and electronic properties of hydrated hydride ion clusters are listed in Table II. The coordination numbers for the hydride ions are 3 for the tri- to penta-hydrated systems and 4 for the hexahydrated system. The average distances $r(\mathrm{H}-\mathrm{O})_{1 \text { av }}$ between the hydride ion and the oxygen atoms of primary water molecules increase as the coordination number increases, and thus the distances are almost constant for clusters larger than trihydrated anion. A drastic enhancement of polarizability by hydration is due to the diffuse nature of the anionic state of the hydrated hydride ion clusters. The vertical detachment energy (VDE) increases as the number of water molecules increases.

The hybridization of virtual orbitals of water molecules and the $2 s$ orbital of the hydride ion produces partial interand intramolecular charge transfer. It is interesting to note that the "tweezers" structure of the hexahydrated hydride ion 
Lowest-Energy Hydride-Water Anions at $0 \mathrm{~K}$

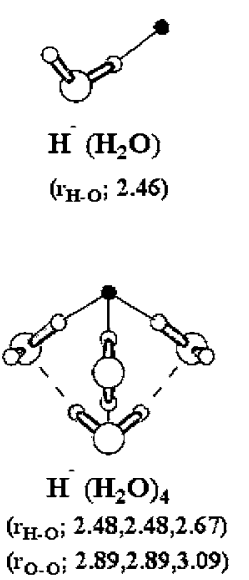

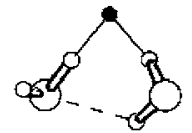

$\mathrm{H}^{-}\left(\mathrm{H}_{2} \mathrm{O}\right)_{2}$

(r $\mathrm{r}_{\mathrm{H}-\mathrm{O}} ; 2.46,2.59$ )

$\left(\mathrm{r}_{\mathrm{O}-\mathrm{O}} ; 3.16\right)$

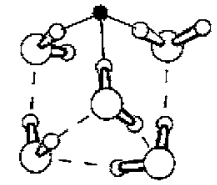

$\mathrm{H}^{-}\left(\mathrm{H}_{2} \mathrm{O}\right)_{5}$

$\left(\mathrm{r}_{\mathrm{H}-\mathrm{O}} ; 2.40,2.53,2.61\right)$

$\left(\mathrm{r}_{0-0} ; 2.86,2.87,2.89\right.$ 2.94,3.02)

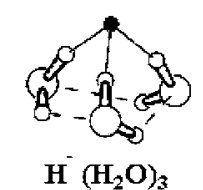

$\left(\mathrm{r}_{\mathrm{H}-\mathrm{O}} ; 2.58,2.58,2.58\right)$

$\left(\mathrm{r}_{\mathrm{O}-0} ; 3.14,3.14,3.14\right)$

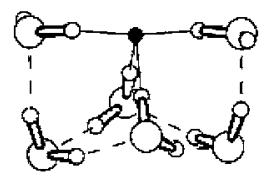

$\mathrm{H}^{-}\left(\mathrm{H}_{2} \mathrm{O}\right)_{6}$

(r. $\left.{ }_{\text {H-O }} ; 2.50,2.50,2.66,2.66\right)$

( $\mathrm{r}_{0}-0 ; 2.86,2.86,2.92,2.92$, $2.94,2.94)$

\section{Entropy-Driven Hydride-Water Anions at $298 \mathrm{~K}$}

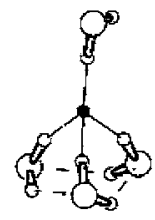

$\mathrm{H}^{-}\left(\mathrm{H}_{2} \mathrm{O}\right)_{4}$

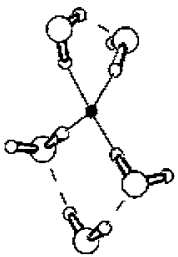

$\mathrm{H}\left(\mathrm{H}_{2} \mathrm{O}\right)_{5}$

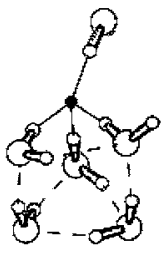

$\mathrm{H}^{-}\left(\mathrm{H}_{2} \mathrm{O}\right)_{6}$
FIG. 2. Low-temperature favorable and room-temperature entropy-driven structures of hydrated hydride anions.

(Fig. 5) is similar to the calculated tweezers form of the anionic water hexamer (which is a local minimum structure). ${ }^{26}$ Figure 5 shows the excited state of the hydride ion in the water hexamer. This excited state includes the diffuse $2 s$ orbital of hydride ion associated with the weak electron transfer to the water cluster.

Hydration studies of anions help to understand the charge-transfer-to-solvent (CTTS) phenomena $^{27}$ via photochemical process. The CTTS energies for the hydrated hydride ion are listed in Table II. The $E_{\mathrm{CT}}^{\mathrm{CIS}}$ and $E_{\mathrm{CT}}^{\mathrm{RPA}}$ tend to be slightly overestimated and underestimated, respectively, as compared to the experimental values. At the B3LYP/6-311 $++\mathrm{G}^{* *}$ level, the highest occupied molecular orbitals (HOMOs) are of the hydride anions, and the lowest unoccupied molecular orbitals (LUMOs) are the hybrid orbitals com-

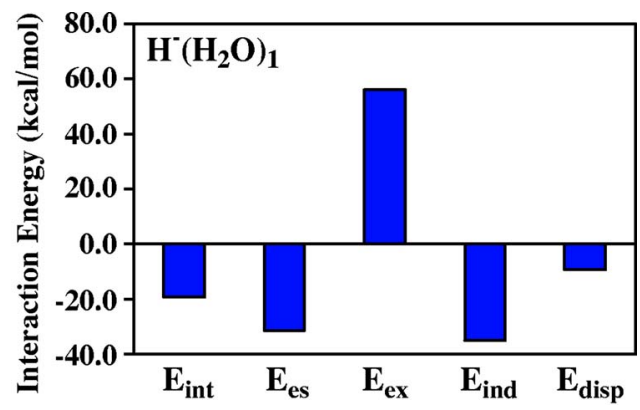

FIG. 3. (Color online) SAPT/aug-cc-pVDZ+ $(2 s 2 p / 2 s)$ interaction energy components of the mono-hydrated hydride ion.

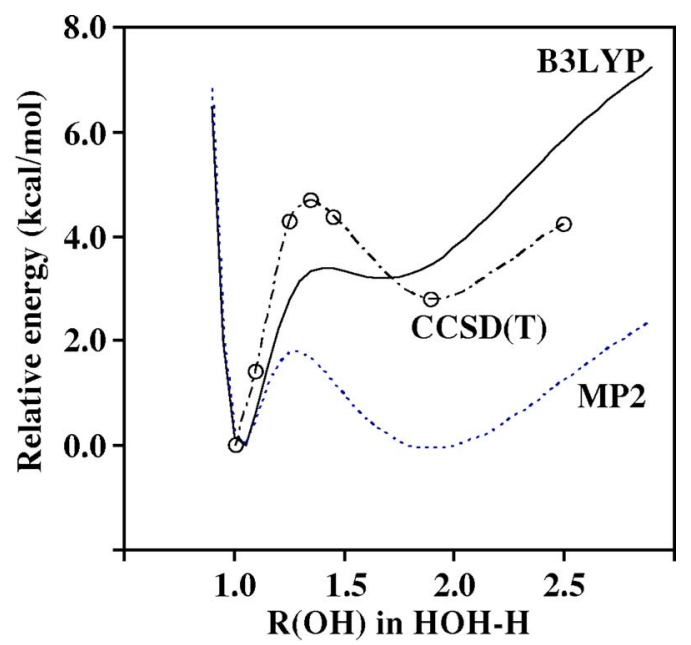

FIG. 4. Potential energy surface (PES) of the proton transfer from water to hydride ion at the B3LYP/6-311++G** MP2/aVDZ+, and $\operatorname{CCSD}(\mathrm{T}) / \mathrm{aVTZ}+$ levels.

prised of the water clusters and the $2 s$ orbital of hydride. Thus, their HOMO-LUMO energy gaps $\left(\delta E_{g}: 371-235 \mathrm{~nm}\right.$ for mono- to hexahydrated hydride-water clusters) provide the information of photoinduced charge transfer from the hydride ion to the water clusters. These low-energy gaps provide somewhat weak charge transfer $\left(0.21 e^{-}-0.37 e^{-}\right)$from the hydride ion to the water molecules due to the low-energy features of the $2 s$ orbital of hydride. As shown in Fig. 5, the diffuse nature of the electron density of the excited hydride anion is similar to that of the electron-water clusters. Thus, the hydration phenomenon of the excited hydride takes place in photoinduced charge-transfer process. The small clusters show weak charge-transfer phenomena accompanying with the release of the $\mathrm{H}$ atom. However, the change from the excited state of hydride-water clusters to the complex of electron-water clusters with the hydrogen radical is exothermic, and the reactions are spontaneous $[0.96 \mathrm{eV}$ for $\mathrm{H}^{-}\left(\mathrm{H}_{2} \mathrm{O}\right)_{2}, \quad 1.78 \mathrm{eV}$ for $\mathrm{H}^{-}\left(\mathrm{H}_{2} \mathrm{O}\right)_{4}$, and $2.47 \mathrm{eV}$ for $\mathrm{H}^{-}\left(\mathrm{H}_{2} \mathrm{O}\right)_{6}$ at the MP2/aVDZ+ level]. The electron-water plus $\mathrm{H}$ radical system is more stable than the $\mathrm{H}^{-*}\left(\mathrm{H}_{2} \mathrm{O}\right)_{n}$ system. Thus, the $\mathrm{H}$ detachment process is possible through CTTS.

\section{E. Hydration and photodynamics of hydrated hydrides}

The entropy-driven structures for $n=4,5$, and 6 at $298 \mathrm{~K}$ at the B3LYP/6-311++ $\mathrm{G}^{* *}$ level are in Fig. 2. At the MP2/aVDZ+ level with the B3LYP/6-311++ $\mathrm{G}^{* *}$ thermal corrections, the surface-bound structure is lower in energy by $0.9 \mathrm{kcal} / \mathrm{mol}$ than the internally bound structure at $0 \mathrm{~K}$ but it becomes higher in energy by $1.4 \mathrm{kcal} / \mathrm{mol}$ at $298 \mathrm{~K}$. The B3LYP/6-311+ $+\mathrm{G}^{* *}$ free energies at room temperature show the more relaxed $\mathrm{H}$-bonded structures of dihydrated hydride ion as the lowest energy structure due to the entropy effect. In the $300 \mathrm{~K}$ DFT-MD simulations, the surface-bound hydride (which is a global minimum at $0 \mathrm{~K}$ ) transformed into the internally bound structure, as shown in Fig. 6. The DFT-MD H- $\left.\mathrm{H}_{2} \mathrm{O}\right)_{4}$ structure at $300 \mathrm{~K}$ is very similar to the entropy driven 4R3I1 structure of $\mathrm{H}^{-}\left(\mathrm{H}_{2} \mathrm{O}\right)_{4}$ which was obtained from the stationary state calculation. The DFT-MD 
TABLE II. Geometric parameters and electronic properties of the hydride anion and hydrated hydride anions. (cn/hb is the number of coordination of the hydride ion/the number of the water-water $\mathrm{H}$ bonds. $r_{\mathrm{H} . . . \mathrm{O}}$ is the average distance between the hydride anion and the oxygen atoms of primary water molecules. The charge $\left(q_{\mathrm{H}_{-}}\right)$of hydrated hydride ion is the MP2/aVDZ+ natural bond orbital (NBO) charge (and B3LYP/6-311++G ${ }^{* *}$ Mulliken charge in brackets). $\delta E_{g}$ is the HOMO-LUMO energy gap at the B3LYP/6-311++ $\mathrm{G}^{* * *}$ level. $\mu_{\text {neut }}$ is the dipole moment of the geometry at the neutral state. $\alpha_{\text {vec }}$ is the polarizability vector at the $\mathrm{B} 3 \mathrm{LYP} / 6-311++\mathrm{G}^{* *}$ level. VDE is vertical-electron detachment energy in eV at the MP2/aVDZ+ level. $E_{\mathrm{CT}}^{\mathrm{CIS}}$ and $E_{\mathrm{CT}}^{\mathrm{RPA}}$ are the CTTS energies (in $\mathrm{nm}$ ) at the CIS and B3LYP(RPA) $/ 6-311+\mathrm{G}^{* * *}$ levels. $q_{\mathrm{H}_{-}}^{\mathrm{CIS}(\text { vert, adia) }}$ are the vertically and adiabatically transferred NBO charges of the hydrated hydride anions via the CTTS process at the CIS/aVDZ+ level. $R+\delta \mathrm{R}_{\mathrm{CT}}$ is the shortest distance (in $\AA$ ) between the hydride ion and the oxygen atom of water at the vertically excited state, plus the increased distance for the optimized CTTS state at the CIS/aVDZ+ level.)

\begin{tabular}{|c|c|c|c|c|c|c|c|c|c|c|c|}
\hline$n$ & $\mathrm{cn} / \mathrm{hb}$ & $r_{\mathrm{H} \ldots \mathrm{O}}$ & $q_{\mathrm{H}_{-}}$ & $\mu_{\text {neut }}$ & $\alpha_{\mathrm{vec}}$ & VDE & $\delta E_{g}$ & $E_{\mathrm{CT}}^{\mathrm{CIS}}$ & $E_{\mathrm{CT}}^{\mathrm{RPA}}$ & $R+\delta \mathrm{R}_{\mathrm{CT}}$ & $q_{\mathrm{H}_{-}}^{\mathrm{CIS}(\mathrm{vert}, \mathrm{opt})}$ \\
\hline 0 & & & $-1.00[-1.00]$ & $\cdots$ & 1.3 & $0.35[0.69,0.69]$ & 4.61 & $\cdots$ & $\cdots$ & $\cdots$ & $\cdots$ \\
\hline 1 & $1 / 0$ & 2.46 & $-0.79[-0.84]$ & 2.23 & 95.9 & $1.38[1.56,1.59]$ & 3.34 & 597 & 447 & $2.46+0.95$ & $-0.52,-0.56$ \\
\hline 2 & $2 / 1$ & 2.52 & $-0.72[-0.71]$ & 2.61 & 89.8 & $2.26[2.37,2.41]$ & 3.82 & 473 & 384 & $2.52+0.83$ & $-0.25,-0.41$ \\
\hline 3 & $3 / 3$ & 2.58 & $-0.71[-0.61]$ & 1.59 & 94.2 & $2.95[3.03,3.08]$ & 4.52 & 343 & 314 & $2.58+2.96$ & $-0.18,-0.48$ \\
\hline 4 & $3 / 3$ & 2.54 & $-0.66[-0.56]$ & 3.88 & 106.3 & $3.47[3.52,3.57]$ & 4.83 & 299 & 290 & $2.54+1.53$ & $-0.02,-0.21$ \\
\hline 5 & $3 / 5$ & 2.51 & $-0.63[-0.54]$ & 7.02 & 117.9 & $3.86[3.89, \ldots]$ & 4.66 & 277 & 306 & $2.51+1.60$ & $0.01,-0.08$ \\
\hline 6 & $4 / 6$ & 2.58 & $-0.67[-0.55]$ & 5.58 & 135.7 & $4.32[4.35, \ldots]$ & 5.27 & 246 & 270 & $2.58+1.53$ & $0.02,-0.11$ \\
\hline
\end{tabular}

energy profiles and geometrical features for $\mathrm{H}^{-}\left(\mathrm{H}_{2} \mathrm{O}\right)_{2}$ are in Fig. 6. At room temperature, the water-water distances fluctuate, so the cluster undergoes the structural fluctuation due to the large entropy. This indicates that the structure is somewhat fluxional at room temperature.

The low-energy unoccupied molecular orbital states lead to the excitation of the hydride ion before the rearrangement of waters and the rehybridization of solvent virtual orbitals with the hydride $2 s$ orbital. However, the ES-AIMD simulations for the dihydrated hydride ion at the CASSCF $(6,6) / a V D Z+$ level show the H-released structures, as shown in Fig. 7, where the potential energy surface (PES) for this process is also given. The ground state of dihydrated hydride at 0 fs shows the lowest energy equilibrium state. The energy of the excited state structure smoothly decreases up to $\sim 160 \mathrm{fs}$, showing the detachment process of the hy-

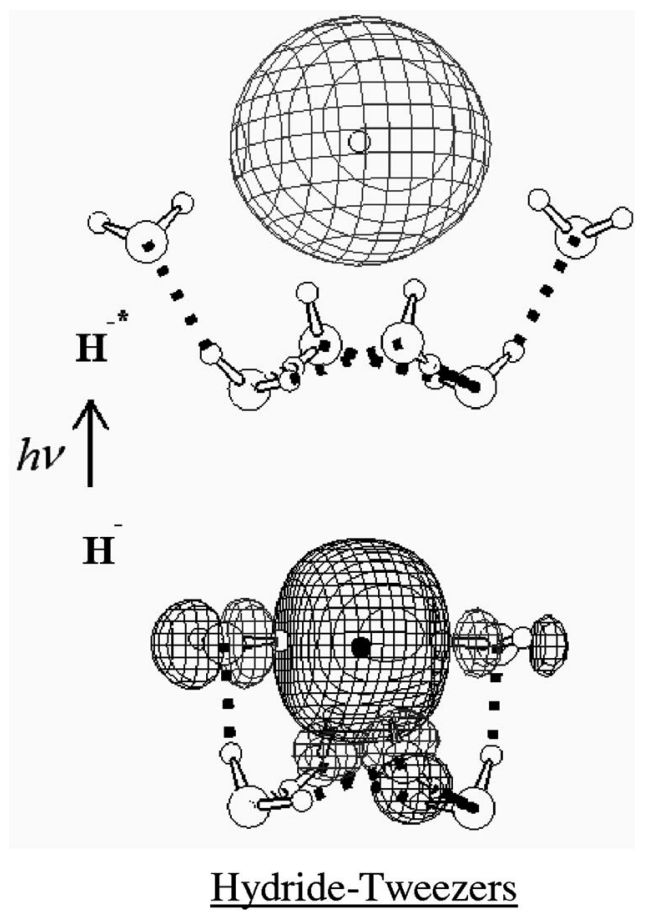

FIG. 5. Ground and excited states of the hexahydrated hydride tweezers. The excited state would reflect the virtual $2 s$ orbital of the hydride ion. drogen radical. In Fig. 7, the kinetic energy of the excited state of the dihydrated hydride ion does not significantly change after $\sim 120 \mathrm{fs}$. The kinetic energy of the hydrogen radical (formed by charge transfer for the hydride ion) is much larger than those of two water molecules. Thus, the total kinetic energy is almost same with the kinetic energy of the hydride atom (which is actually a neutralized hydrogen atom), and the kinetic energies of two water molecules are near zero. The distances between the hydrogen radical and two water molecules monotonically increase, showing the detachment of the hydrogen radical, as shown in Fig. 7(b). The water-water distance does not show a large change. Figure $7(\mathrm{c})$ reveals the variation of the natural bond orbital ${ }^{28}$ (NBO) charges along the detachment process of hydrogen atom in the excited-state dynamics process. Around $130 \mathrm{fs}$, the NBO charge of hydride (neutralized hydrogen atom) converged to zero and the NBO charge of acceptor water (Wa) molecule shows the converged value of about -0.9 a.u. in Fig. 8(c) (with no further significant change after $130 \mathrm{fs}$ ). Figure 7(d) shows the singly occupied molecular orbital states of the excited dihydrated hydride at $0,40,80$, and $200 \mathrm{fs}$ along the excited-state dynamics process. The
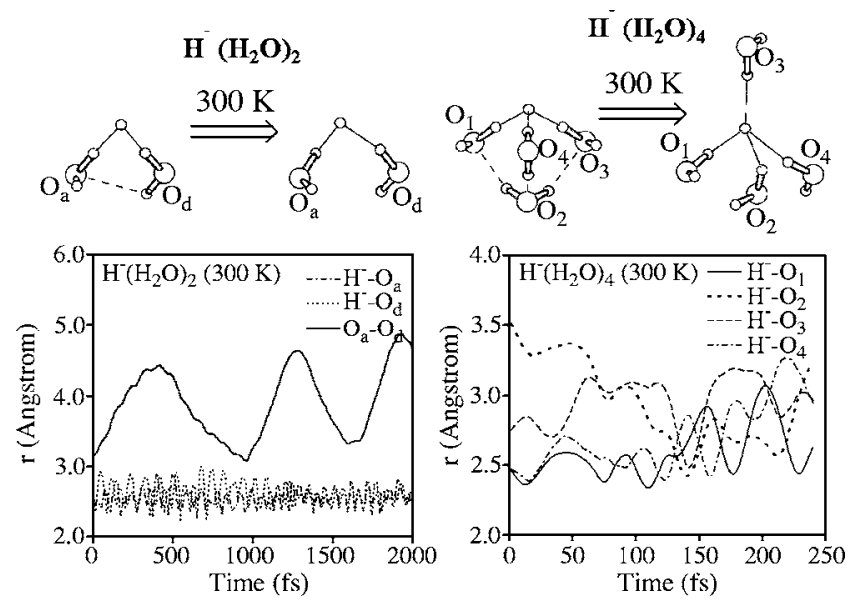

FIG. 6. B3LYP/6-311++ $\mathrm{G}^{* *}$ DFT-MD simulations of $\mathrm{H}^{-}\left(\mathrm{H}_{2} \mathrm{O}\right)_{2}$ and $\mathrm{H}^{-}\left(\mathrm{H}_{2} \mathrm{O}\right)_{4}$ at $300 \mathrm{~K}$. The geometrical structures at the beginning and at the end of the simulations are shown. The subscripts $a$ and $d$ denote the $\mathrm{H}$-acceptor and donor water molecules, respectively. 

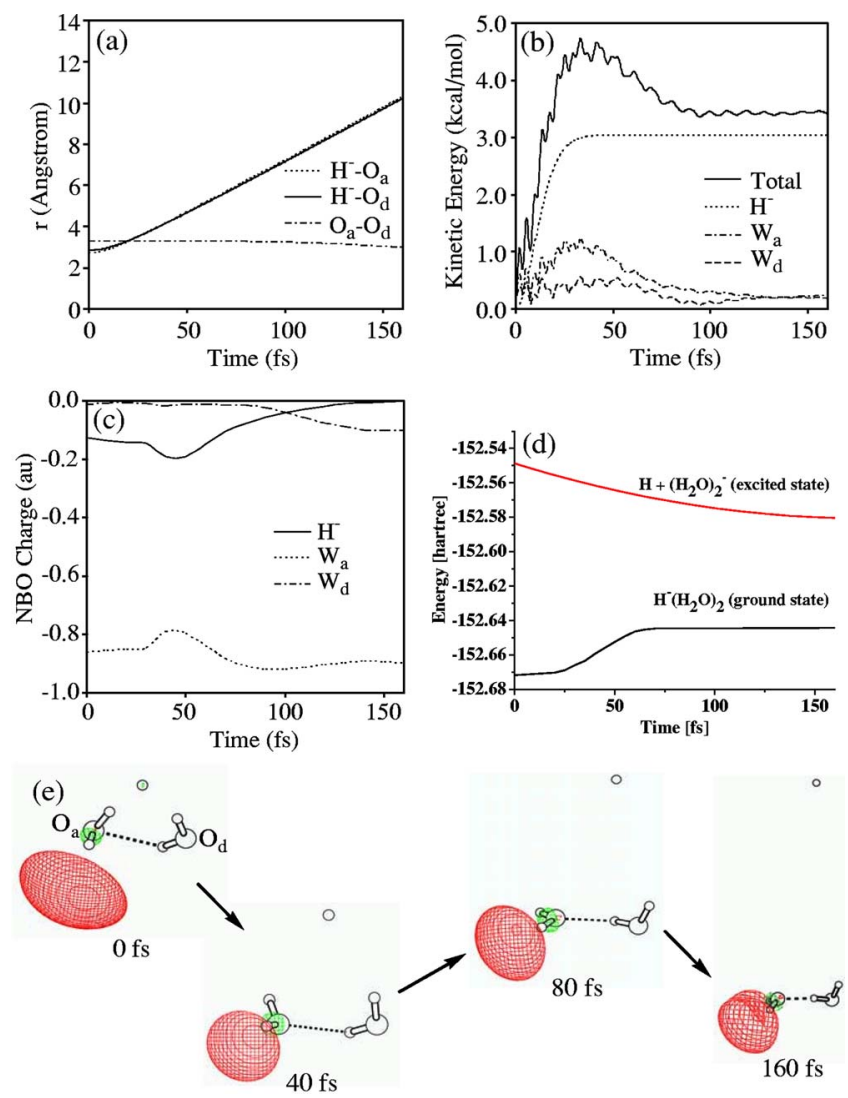

FIG. 7. (Color online) Excited-state $\operatorname{CASSCF}(6,6) / a V D Z+$ AIMD simulations of $\mathrm{H}^{-}\left(\mathrm{H}_{2} \mathrm{O}\right)_{2}$ at $0 \mathrm{~K}$. The distance between the hydride ion and the nearest $\mathrm{O}$ atom in the water cluster $(\AA)(\mathrm{a})$, evolution of kinetic energies $(\mathrm{kcal} / \mathrm{mol})(\mathrm{b}), \mathrm{NBO}$ charges of the hydride ion (c), potential energy surface (d) along the excited-state MD trajectory (e). The detachment of the hydrogen radical is clearly seen.

electron-water dimer structure was formed in this simulation process, as already found to be an exothermic and spontaneous reaction.

\section{F. IR spectra of hydrated hydrides}

The B3LYP/6-311++ $\mathrm{G}^{* *}$ infrared (IR) spectra for $\mathrm{OH}$ stretching modes of hydrated hydride anions are in Fig. 8 and the frequencies are listed in Table III. The frequencies were
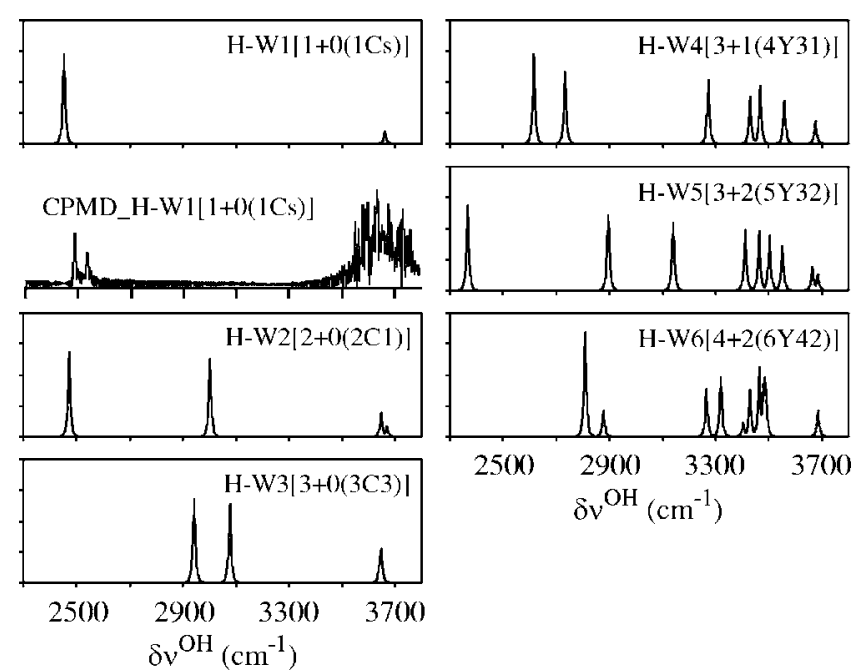

FIG. 8. B3LYP/6-311++ $\mathrm{G}^{* *}$ IR spectra for the OH stretches of the hydrated hydride ion clusters (scale factor: 0.96). The second figure of IR spectra was of monohydrated hydride from the CPMD calculation at $100 \mathrm{~K}$ (scale factor; 1.025).

scaled by 0.96 to match the average value of asymmetric and symmetric stretch frequencies of $\mathrm{H}_{2} \mathrm{O}$ with the corresponding experimental value. ${ }^{29}$ The $\mathrm{OH}$ stretching frequency of the $\mathrm{OH}$ group interacting with the hydride ion in the monohydrated hydride anion is considerably redshifted with respect to the average value of asymmetric and symmetric $\mathrm{OH}$ stretching frequencies of the pure water monomer. The $\mathrm{OH}$ stretching frequencies of $1 \mathrm{Cs}, 2 \mathrm{C} 1,3 \mathrm{C} 3,4 \mathrm{Y} 31,5 \mathrm{Y} 32$, and 6 Y42 are redshifted by $1305,1285,792,1134,1395$, and $932 \mathrm{~cm}^{-1}$ due to the charge-water interactions. These magnitudes are considerable as compared to those of other ionwater clusters, indicating low-energy barriers for the proton transfer in the hydride-water interaction. We have calculated the monohydrated hydride anion using CPMD simulation with the hybrid B3LYP functional and BLYP pseudopotentials at $100 \mathrm{~K}$. The obtained spectrum of monohydrated hydride anion is drawn in the second figure of the IR spectra in Fig. 8. The scale factor of 1.025 was used for this small system. ${ }^{14,30}$ The $\mathrm{H}$-bonding and nonbonding $\mathrm{OH}$ stretching frequencies at the CPMD simulation is similar to those at the B3LYP level.

TABLE III. B3LYP/6-311++ $\mathrm{G}^{* *}$ scaled frequencies $\left(\nu^{\mathrm{OH}}\right.$ and $\nu^{\mathrm{HOH}}$ in $\left.\mathrm{cm}^{-1}\right)$ and IR intensities (in $10 \mathrm{~km} / \mathrm{mol}$ in parentheses) for the OH stretching and bending modes of hydrated hydride ions, $\mathrm{H}^{-}\left(\mathrm{H}_{2} \mathrm{O}\right)_{n=1-6}$. The frequencies were scaled by 0.96 to match the average value of asymmetric and symmetric stretch frequencies of $\mathrm{H}_{2} \mathrm{O}$ with the corresponding experimental value (Ref. 29). Superscripts I, W, and D indicate the OH stretches of ion-water interaction, water-water H-bond interaction, and free dangling H, respectively. Subscripts a, da, dda, and d denote a-, da-, dda-, and d-type water molecules, where a and $\mathrm{d}$ mean the $\mathrm{H}$ acceptor and donor, respectively.

\begin{tabular}{lll}
\hline \hline$n$ & $-\delta_{\nu}^{\mathrm{OH}}$ & \multicolumn{1}{c}{$\delta_{\nu_{2}}^{\mathrm{HOH}}$} \\
\hline 1 & $2452(170)^{\mathrm{I}}, 3661(1)^{\mathrm{D}}$ & $1578(9)$ \\
2 & $2471(152)^{\mathrm{I}}, 3002(112)^{\mathrm{I}}, 3647(4)^{\mathrm{D}}, 3669(0)^{\mathrm{D}}$ & $1618(13), 1583(6)$ \\
3 & $2942(80)^{\mathrm{I}}, 2942(80)^{\mathrm{I}}, 3077(119)^{\mathrm{I}}, 3642(3)^{\mathrm{D}}, 3647(4)^{\mathrm{D}}, 3647(4)^{\mathrm{D}}$ & $1613(6), 1609(12), 1609(12)$ \\
4 & $2616(182)_{\mathrm{a}}^{\mathrm{I}}, 2734(91)_{\mathrm{a}}^{\mathrm{I}}, 3273(56)_{\mathrm{d}}^{\mathrm{I}}, 3431(26)_{\mathrm{dda}}^{\mathrm{W}}, 3468(44)_{\mathrm{dda}}^{\mathrm{W}}$, & $1660(11)_{\mathrm{dda}}, 1619(3)_{\mathrm{d}}, 1597(12)_{\mathrm{a}}$, \\
& $3560(22)_{\mathrm{d}}^{\mathrm{W}}, 3676(2)_{\mathrm{a}}^{\mathrm{D}}, 3677(1)_{\mathrm{a}}^{\mathrm{D}}$ & $1589(2)_{\mathrm{a}}^{\mathrm{a}}$ \\
5 & $2367(152)_{\mathrm{a}}^{\mathrm{I}}, 2896(111)_{\mathrm{a}}^{\mathrm{I}}, 3141(71)_{\mathrm{da}}^{\mathrm{I}}, 3412(52)_{\mathrm{dda}}^{\mathrm{W}}, 3416(1)_{\mathrm{dda}}^{\mathrm{W}}$, & $1655(11)_{\mathrm{dda}}, 1636(4)_{\mathrm{dda}}, 1619(9)_{\mathrm{a}}$, \\
& $3464(46)_{\mathrm{dda}}^{\mathrm{W}}, 3504(45)_{\mathrm{dda}}^{\mathrm{W}}, 3552(22)_{\mathrm{da}}^{\mathrm{W}}, 3665(3)_{\mathrm{a}}^{\mathrm{D}}, 3685(1)_{\mathrm{a}}^{\mathrm{D}}$ & $1610(4)_{\mathrm{da}}, 1579(8)_{\mathrm{a}}$ \\
& $2809(265)_{\mathrm{a}}^{\mathrm{I}}, 2879(5)_{\mathrm{a}}^{\mathrm{I}}, 3266(27)_{\mathrm{da}}^{\mathrm{I}}, 3320(50)_{\mathrm{da}}^{\mathrm{I}}, 3404(1)_{\mathrm{dda}}^{\mathrm{W}}, 3430(29)_{\mathrm{dda}}^{\mathrm{W}}$, & $1663(10)_{\mathrm{dda}}, 1656(12)_{\mathrm{dda}}, 1635(4)_{\mathrm{da}}$, \\
& $3465(87)_{\mathrm{da}}^{\mathrm{W}}, 3480(34)_{\mathrm{dda}}^{\mathrm{W}}, 3487(46)_{\mathrm{da}}^{\mathrm{W}}, 3491(20)_{\mathrm{dda}}^{\mathrm{W}}, 3686(3)_{\mathrm{a}}^{\mathrm{D}}, 3686(1)_{\mathrm{a}}^{\mathrm{D}}$ & $1622(11)_{\mathrm{da}}, 1590(6)_{\mathrm{a}}, 1587(0)_{\mathrm{a}}$ \\
\hline \hline
\end{tabular}




\section{CONCLUDING REMARKS}

Structures of the hydrated hydride anion were investigated. The lowest energy conformers of mono- to hexahydrated hydride anions were calculated as $1 \mathrm{Cs}, 2 \mathrm{C} 1,3 \mathrm{C} 3$, $4 \mathrm{Y} 31,5 \mathrm{Y} 32$, and $6 \mathrm{Y} 42$ at $0 \mathrm{~K}$ at the levels of B3LYP/6-311++ G** $^{* *}$ and MP2/aVDZ+ theory. The CCSD(T)/CBS calculations were also carried out. At $298 \mathrm{~K}$, the tetra- to hexa-hydrated hydride anions change to the entropy driven structures of 4R3I1, 5I32, and 6Y32I1. The IR spectra were investigated at the B3LYP level and at the CPMD simulation level. The DFT-MD simulations of di- and tetra-hydrated hydride ions were performed. As the temperature increases to room temperature, the surface-bound structures transformed to internally bound structures. The photodynamics of dihydrated hydride ion shows the charge transfer from the hydride ion to the water cluster, and the hydrogen detachment phenomenon takes place, as in the photodynamics of iodide-water clusters. In the photoreactions of hydrated hydride ions, the CTTS phenomenon drives the detachment of $\mathrm{H}$ atoms and the production of electronwater clusters.

\section{ACKNOWLEDGMENTS}

This work was supported by the Korea Research Foundation Grant (KRF-2006-353-C00022) funded by Korea Government (MOEHRD), the Global Research Laboratory Project (KICOS), and BK21. One of the authors (H.M.L.) would like to acknowledge the support from KISTI under the Strategic Supercomputing Support Program.

${ }^{1}$ J. M. Berg, J. L. Tymoczko, and L. Stryer, Biochemistry (W. H. Freeman and Company, New York, 2002).

${ }^{2}$ A. Kobayashi, R. Takatori, I. Kikuchi, H. Konno, K. Sakamoto, and O. Ishitani, Organometallics 20, 3361 (2001); P. Skae and R. J. Parry, Org. Lett. 3, 1117 (2001).

${ }^{3}$ K. P. Hurber and G. Herberg, Molecular Spectra and Molecular Structure (Van Nostrand, Amsterdam, 1979), Vol. IV; V. M. Garcia, R. Caballel, and J. P. Malrieu, J. Chem. Phys. 109, 504 (1998).

${ }^{4}$ X. Wang and L. Andrews, J. Am. Chem. Soc. 123, 12899 (2001).

${ }^{5}$ S. Buckart, G. Gantefor, Y. D. Kim, and P. Jena, J. Am. Chem. Soc. 125, 14205 (2003); P. Schwerdtfeger, P. D. W. Boyd, S. Brienne, and A. K. Burrell, Inorg. Chem. 31, 3411 (1992) and references therein; C. A. Bayse and M. B. Hall, J. Am. Chem. Soc. 121, 1348 (1999); C. A. Bayse, J. Phys. Chem. A 105, 5902 (2001); N. B. Balabanov and J. E. Boggs, ibid. 105, 5906 (2001).

${ }^{6}$ E. E. Muschlitz, Jr., J. Appl. Phys. 28, 1414 (1957).

${ }^{7}$ R. E. Kari and I. G. Csizimadia, J. Am. Chem. Soc. 99, 4539 (1977); J. F. Paulson and M. J. Henchman, Bull. Am. Phys. Soc. 27, 108 (1982); J. C. Kleingeld and N. M. M. Nibbering, Int. J. Mass Spectrom. Ion Phys. 49, 311 (1983).

${ }^{8}$ T. M. Miller, A. A. Viggiano, A. E. S. Miller, R. A. Morris, M. Henchman, J. F. Paulson, and J. M. Van Doren, J. Chem. Phys. 100, 5706 (1994).

${ }^{9}$ C. D. Richie and H. F. King, J. Am. Chem. Soc. 88, 1069 (1966); 90, 825 (1968); 90, 833 (1968); 90, 838 (1968); C. J. Glidewell, J. Mol. Struct. 67, 121 (1980); D. Cremer and E. Kraka, J. Phys. Chem. 90, 33 (1986).

${ }^{10}$ G. Chalasinski, R. A. Kendall, and J. Simons, J. Chem. Phys. 87, 2965 (1987); S. S. Xantheas and T. H. Dunning, Jr., J. Phys. Chem. 96, 7505 (1992).

${ }^{11}$ H. M. Lee, S. B. Suh, and K. S. Kim, J. Chem. Phys. 119, 7685 (2003); A. Kumar, M. Park, J. Y. Huh, H. M. Lee, and K. S. Kim, J. Phys. Chem. A 110, 12484 (2006).
${ }^{12}$ J. E. Huheey, E. A. Keiter, and R. L. Keiter, in Inorganic Chemistry: Principles and Structure and Reactivity, edited by J. Piro (Harper Collins, New York, 1993)

${ }^{13}$ K. S. Kim, P. Tarakeshwar, and J. Y. Lee, Chem. Rev. (Washington, D.C.) 100, 4145 (2000); J. Kim and K. S. Kim, J. Chem. Phys. 109, 5886 (1998); B. J. Mhin, J. Kim, S. Lee, J. Y. Lee, and K. S. Kim, ibid. 100, 4484 (1994); K. S. Kim, B. J. Mhin, U.-S. Choi, and K. Lee, ibid. 97, 6649 (1992); H. M. Lee, S. B. Suh, J. Y. Lee, P. Tarakeshwar, and K. S. Kim, ibid. 112, 9759 (2000).

${ }^{14}$ I. Shin, M. Park, S. K. Min, E. C. Lee, S. B. Suh, and K. S. Kim, J. Chem. Phys. 125, 234305 (2006); E. C. Lee, D. Kim, P. Jurečka, P. Tarakeshwar, P. Hobza, and K. S. Kim, J. Phys. Chem. A 111, 3446 (2007); J. M. L. Martin, ACS Symp. Ser. 677, 212 (1998); T. Helgaker, W. Klopper, H. Koch, J. Noga, J. Chem. Phys. 106, 9639 (1997).

${ }^{15}$ M. E. Casida, C. Jomorski, K. C. Casida, and D. R. Salahub, J. Chem. Phys. 108, 4439 (1998).

${ }^{16}$ M. J. Frisch, G. W. Trucks, H. B. Schlegel et al., Gaussian03, Revision A.1., Gaussian, Inc., Pittsburgh, PA, 2003.

${ }^{17}$ B. Jeziorski, R. Moszynski, A. Ratkiewicz, S. Rybak, K. Szalewicz, and H. L. Williams, Methods and Techniques in Computational Chemistry: METECC-94, Medium Size Systems, edited by E. Clementi (STEF, Cargliari, 1993), Vol. B.

${ }^{18}$ M. Dupuis, A. Marquez, and E. R. Davidson, HONDO99.6, 1999, based on HOND095.3 by M. Dupuis, A. Marquez, and E. R. Davidson, Quantum Chemistry Program Exchange (QCPE), Indiana University, Bloomington, IN.

${ }^{19}$ CPMD, version 3.9; IBM Corp., MPI Für Festkörperforschung:Stuttgart, Germany, 1990-2004, 1997-2001; http://www.cpmd.org/

${ }^{20}$ S. J. Lee, H. Y. Chung, and K. S. Kim, Bull. Korean Chem. Soc. 25, 1061 (2004).

${ }^{21}$ W. H. Robertson, E. G. Diken, E. A. Price, J.-W. Shin, and M. A. Johnson, Science 299, 1367 (2003); G. Markkovich, R. Giniger, M. Levin, and O. Cheshnovsky, J. Chem. Phys. 95, 9416 (1991); G. Markovich, S. Pollack, R. Giniger, and O. Cheshnovsky, ibid. 101, 9344 (1994); S. J. Vanghn, E. V. Akhmatskaya, M. A. Vincent, A. J. Masters, and I. H. Hillier, ibid. 110, 4338 (1999).

${ }^{22}$ J. Baik, J. Kim, D. Majumdar, and K. S. Kim, J. Chem. Phys. 110, 9116 (1999); J. E. Combariza and N. R. Kestner, J. Phys. Chem. 98, 3513 (1994); J. E. Combariza, N. R. Kestner, J. Jortner, J. Chem. Phys. 100, 2851 (1994); S. S. Xantheas, T. H. Dunning, Jr., J. Phys. Chem. 98, 13489 (1994); H. M. Lee and K. S. Kim, Mol. Phys. 100, 875 (2002); J. M. Weber, J. A. Kelley, S. B. Nielsen, P. Ayotte, and M. A. Johnson, Science 287, 2461 (2000).

${ }^{23}$ H. M. Lee, P. Tarakeshwar, and K. S. Kim, J. Chem. Phys. 121, 4657 (2004); J. Kim, H. M. Lee, S. B. Suh, D. Majumdar, and K. S. Kim, J. Chem. Phys. 113, 5259 (2000); H. M. Lee, D. Kim, and K. S. Kim, ibid. 116, 5509 (2002); M. Kolaski, H. M. Lee, C. Pak, M. Dupuis, and K. S. Kim, J. Phys. Chem. A 109, 9419 (2005).

${ }^{24}$ H. M. Lee, S. B. Suh, P. Tarakeshwar, and K. S. Kim, J. Chem. Phys. 122, 044309 (2005); H. M. Lee, S. Lee, and K. S. Kim, ibid. 119, 187 (2003); S. B. Suh, H. M. Lee, J. Kim, J. Y. Lee, and K. S. Kim, ibid. 113, 5273 (2000); J. Kim and K. S. Kim, ibid. 111, 10077 (1999); J. Kim, J. Y. Lee, K. S. Oh, J. M. Park, S. Lee, and K. S. Kim, Phys. Rev. A 59, R930 (1999).

${ }^{25}$ G. N. Patwari, A. Fujii, and N. Mikami, J. Chem. Phys. 124, 241103 (2006); D. Donghi, T. Beringhelli, G. D'Alfonso, and M. Mondini, Chem.-Eur. J. 12, 1016 (2006); J. C. Lee, A. L. Rheingold, B. Muller, P. S. Pregosin, and R. H. Crabtree, J. Chem. Soc., Chem. Commun. 1994, 1021; A. J. Lough, S. Park, R. Ramachadran, and R. H. Morris, J. Am. Chem. Soc. 116, 8356 (1994); R. Custelcean and J. E. Jackson, Chem. Rev. (Washington, D.C.) 101, 1963 (2001); I. Alkorta, I. Rozas, and J. Elguero, Chem. Soc. Rev. 27, 163 (1998); T. R. Richardson, S. Gala, R. H. Crabtree, and P. E. M. Siegbahn, J. Am. Chem. Soc. 118, 12875 (1996); N. V. Belkova, M. Besora, L. M. Epstein, A. Lledos, F. Maseras, and E. S. Shubina, ibid. 125, 7715 (2003); N. V. Belkova, P. O. Revin, L. M. Epstein, E. V. Vorontsov, V. I. Bakhmutov, E. S. Shubina, E. Collange, and R. Poli, ibid. 125, 11106 (2003); D. G. Gusev, A. J. Lough, and R. H. Morris, ibid. 120, 13138 (1998).

${ }^{26}$ K. S. Kim, S. Lee, J. Kim, and J. Y. Lee, J. Am. Chem. Soc. 119, 9329 (1997); S. Lee, J. Kim, S. J. Lee, and K. S. Kim, Phys. Rev. Lett. 79, 2038 (1997); H. M. Lee, S. Lee, and K. S. Kim, J. Chem. Phys. 119, 187 (2003). 
${ }^{27}$ D. Majumdar, J. Kim, and K. S. Kim, J. Chem. Phys. 112, 101 (2000); H.M. Lee and K. S. Kim, ibid. 114, 4461 (2001).

${ }^{28}$ J. E. Carpenter and F. Weinhold, J. Mol. Struct.: THEOCHEM 169, 41 (1988); A. E. Reed, L. A. Curtiss, and F. Weinhold, Chem. Rev. (Washington, D.C.) 88, 899 (1988).
${ }^{29}$ P. E. Fraley and K. N. Rao, J. Mol. Spectrosc. 29, 348 (1969); U. Buck and F. Huisken, Chem. Rev. (Washington, D.C.) 100, 3863 (2000).

${ }^{30}$ N. J. Singh, M. Park, S. K. Min, S. B. Suh, and K. S. Kim, Angew. Chem., Int. Ed. 45, 3795 (2006); Angew. Chem. 118, 3879 (2006). 